\title{
Carl Rogers e a Recepção da Fenomenologia na Psicologia Estadunidense
}

\author{
Paulo Coelho Castelo Branco ${ }^{1, *}$ (1) \& Sérgio Dias Cirino² (1) \\ 'Universidade Federal do Ceará, Fortaleza, Ceará, Brasil \\ ${ }^{2}$ Universidade Federal de Minas Gerais Belo Horizonte, Minas Gerais, Brasil
}

\begin{abstract}
RESUMO - Objetivou-se revisitar a relação de Rogers com o movimento de recepção da Fenomenologia na Psicologia estadunidense, empregando a noção historiográfica de recepção para investigar o que foi contatado por ele, em seus aspectos históricos internalistas e externalistas. Baseados nas menções de Rogers à Fenomenologia, identificaram-se sete momentos característicos de tal relação, entre 1940-1970. Como resultado, foi constatado que a Fenomenologia que Rogers menciona não é a oriunda da Filosofia europeia, mas advém de um paradigma de ciência alternativo ao positivismo hegemônico no behaviorismo. No contexto clínico, Rogers percebeu implicações desse movimento para o desenvolvimento de pesquisas e intervenções sobre o self. No campo filosófico, ele esboçou uma teoria do conhecimento baseada na experiência tácita e pré-conceitual. Na pesquisa, ele foi simpático ao desenvolvimento de investigações fenomenológicas empíricas, mas não chegou a desenvolver uma. Conclui-se que a Filosofia fenomenológica não influenciou diretamente Rogers, mas o movimento fenomenológico na Psicologia estadunidense sim.
\end{abstract}

PALAVRAS-CHAVE: Carl Rogers, fenomenologia, história da psicologia, terapia centrada no cliente

\section{Carl Rogers and the Phenomenology' Reception in American Psychology}

\begin{abstract}
We aim to revisit Rogers' relationship with the reception movement of Phenomenology in American Psychology. We use the historiographical notion of reception to investigate what was contacted in its internal-external historical aspects. Based on the Rogers mentions to the Phenomenology, we identify seven moments of such relationship, among 1940-1970. The Phenomenology that Rogers mentions does not derives from the European Philosophy, but it rather comes from a paradigm alternative to the hegemonic positivism in the behaviorism. In the clinic, Rogers perceived the implications of this movement for the development of research and interventions on the self. In the philosophy, he outlined a knowledge theory, based on tacit and pre-conceptual experiences. In the research, he was sympathetic to the development of empirical phenomenological investigations but did not develop any. We conclude that the phenomenological Philosophy did not influence Rogers directly, but the phenomenological movement in American Psychology did.
\end{abstract}

KEYWORDS: Carl Rogers, phenomenology, history of psychology, Client-centered therapy

Carl Rogers teve uma trajetória acadêmica e intelectual que apresentou variadas influências nos campos da Psicologia, Psicoterapia e Filosofia. Ele estabeleceu relações com diversos estudantes, colaboradores e pensadores que contribuíram para a constituição e ampliação do seu pensamento. Apesar disso, o expoente humanista não se preocupou em organizar um lastro histórico dessas influências, deixando esse trabalho para os seus seguidores. Nessa perspectiva, é possível indicar algumas produções nacionais recentes que se preocuparam em investigar as bases do pensamento rogeriano em seus afluentes fenomenológicos, existenciais, pragmáticos-funcionalistas e psicanalíticos (Amatuzzi \& Carpes, 2010; Moreira, 2010a, 2010b; Vieira \& Pinheiro, 2011; Castelo-Branco \& Cirino, 2016a, 2016b; Castelo-Branco et al., 2016b). Com inspiração no trabalho de resgate histórico das influências de Rogers, objetivou-se

\footnotetext{
*E-mail: pauloccbranco@gmail.com

- Submetido: 15/03/2017; Aceito: 18/09/2018.
} 
revisitar o contato desse autor com o movimento de recepção da Fenomenologia na Psicologia estadunidense.

Rogers (1961/1997) reconheceu uma aproximação tardia do seu pensamento com a Fenomenologia, ao passo que Herbert Spiegelberg (1972), um historiador do movimento fenomenológico, o mencionou como um representante de tal movimento na Psicologia estadunidense. A despeito disso, existem estudos que argumentam o equívoco de situar Rogers em uma matriz fenomenológica ou de afirmar que a Fenomenologia que o influenciou seja um engano (Moreira, 2010b). A existência de uma discussão sobre a relação de Rogers com a Fenomenologia, entretanto, não está esgotada. $O$ presente artigo assumiu essa contenda com a proposta de responder a duas perguntas lançadas por Spiegelberg (1972), a saber, "O quão diferente é a Fenomenologia Rogers de suas formas tradicionais? Até que ponto ele é devedor da Fenomenologia filosófica?” (p. 149, tradução nossa).

Para auxiliar a (re) construção histórica da relação de Rogers com a Fenomenologia, recorreu-se à noção de recepção (Castelo-Branco et al., 2016a) para investigar quais elementos dessa corrente de pensamento foram contatados e elaborados por ele, nos aspectos internalistas de sua teoria e externalistas ao seu contexto acadêmicocientífico. Entende-se que a noção de recepção alude a um processo de migração de um conhecimento psicológico de um local para outro. Nesse processo, ocorre uma circulação de ideias organizadas e propagadas, num espaço-tempo, em certas operações sociais, como a organização de livros, eventos acadêmicos e a publicação de artigos em periódicos. No caso da Fenomenologia, esta foi recebida nos EUA e foi apropriada pelos psicólogos da época, incluindo Rogers, segundo alguns entendimentos e implicações que distinguiram outro modo de pensamento/aplicação sobre ela, na pesquisa e na clínica. Em outras palavras, existem elementos de recepção da Fenomenologia na Psicologia estadunidense e na Psicologia Humanista de Rogers que implicam uma assimilação e elaboração desse conhecimento que passou a ser apropriado conforme as discussões de um contexto, que o tornou híbrido e singular em relação a sua origem filosófica europeia.

Com efeito, em um esteio cronológico que abrangeu as décadas de 1940-1970, analisaram-se sete momentos que foram julgados como característicos da relação de Rogers com o movimento fenomenológico na Psicologia estadunidense, com amparo em suas menções à Fenomenologia. Ponderouse, ao final, o tipo de relação que Rogers estabeleceu com a Fenomenologia, argumentando uma resposta aos questionamentos de Spiegelberg.

\section{RELAÇÃO DE CARL ROGERS COM DONALD SNYGG E ARTHUR COMBS, NOS ANOS DE 1940-1950}

Alguns trabalhos (Spiegelberg, 1972; Gomes et al., 2004; Moreira, 2010b) apontam que existe uma aproximação da teoria de Carl Rogers com a Fenomenologia, desde a elaboração do conceito de campo fenomenológico ou fenomenal (phenomenological field), procedente de Donald Snygg e Arthur Combs.

Snygg, em 1941, publicou na Psychological Review o artigo intitulado The need for a phenomenological system of psychology. Isso o tornou conhecido como um dos psicólogos pioneiros na constituição do movimento fenomenológico nos EUA (Spiegelberg, 1972). Snygg estudou Psicologia da Gestalt com Wolfgang Köhler na Alemanha, em 1929. Nesse estudo, Snygg enfatizou a importância do campo perceptual para o comportamento, ao elaborar uma distinção entre o que é um ambiente geográfico e um ambiente psicológico, postulando a influência de ambos no comportamento. O termo fenomenológico, no entanto, somente foi integrado ao vocábulo campo em 1935, após o seu doutorado na Universidade de Toronto, onde o seu orientador, William Line, sugeriu o uso dessa palavra para mencionar um quadro de referência central que organiza a percepção, o comportamento e a motivação. Observou-se que a proposta de Snygg não deriva diretamente de uma Filosofia fenomenológica, mas há certa influência indireta dela pela Psicologia de Köhler, para repensar uma perspectiva alternativa à Psicologia Comportamental da época (Spiegelberg, 1972).

No texto mencionado, Snygg argumenta que uma abordagem fenomenológica na Psicologia deve consistir, primariamente, na exploração do campo fenomenológico da pessoa como fonte de constituição da sua personalidade. Para Snygg (1941/1959), o comportamento é determinado pelo campo fenomenológico, um conjunto de percepções que ela tem do organismo e de sua relação com o ambiente. Essas percepções constituem o self e orientam o comportamento de alguém em sua relação com o mundo. Em 1945, Snygg começou a trabalhar com Combs, um ex-doutorando de Rogers.

Em 1947, durante uma conferência proferida no final do seu mandato de presidência na Associação Americana de Psicologia, Rogers, inspirado pelos estudos sobre personalidade que se desenvolviam nos EUA, nos anos de 1930-1940, citou e referenciou um livro de Snygg e Combs no prelo e um artigo de Snygg, sobre um experimento com ratos. Essa palestra foi transcrita, sob o título de Some observations on the organization of personality e publicada, no mesmo ano, na revista The American Psychologist. Nesse texto, Rogers (1947/2008) usa em abundância a dicção campo perceptual como fonte de organização da personalidade e da percepção da realidade que conduzem 
o comportamento. Utilizando exemplos clínicos que demonstram tal relação e como esta afeta processos de ajustamento, Rogers argumenta que a mudança do campo perceptual é a chave clínica para promover uma mudança de personalidade e possibilitar comportamentos mais ajustados aos atributos psicológicos do cliente. É possível, contudo, observar em Rogers a posterior mudança de nomenclatura de campo perceptual para campo fenomenológico.

Inspirado pelo conceito snyggiano de campo fenomenológico, Combs publicou o artigo intitulado Phenomenological concepts in nondirective therapy, em 1948, no Journal of Consulting Psychology. Nesse artigo, Combs (1948) indica que o termo não diretivo é sinônimo ou equivalente a fenomenológico. Possivelmente esse artigo, somado às leituras de Rogers a Snygg, ocasionou tal mudança de nomenclatura no conceito. Em 1951, Rogers publicou o livro Client-Centered Therapy em que, no último capítulo, elabora uma teoria da personalidade e do comportamento. Nessa teoria, sobretudo nas quatro primeiras proposições sobre a estruturação da personalidade, é possível encontrar menções e referência ao trabalho de Snygg e Combs, agora publicado como Individual behavior: a new frame of reference for psychology (1948). No livro de Rogers (1951/1992) existem diversas menções à expressão campo fenomenológico, indicando-a como sinônima de campo perceptual ou campo experiencial.

Torna-se evidente, portanto, a influência do conceito de campo fenomenológico, elaborado por Snygg e desenvolvido em parceria com Combs, sobre a Psicologia clínica de Rogers. Este contatou esse conceito e o elaborou conforme uma teoria da personalidade, indo além de uma perspectiva de Psicologia experimental desenvolvida por Snygg e colaborando com a proposta de um sistema de compreensão fenomenológico na Psicologia, de certa forma.

\section{CONTATO DE CARL ROGERS, NA DÉCADA DE I950, COM DOIS ESTUDANTES EUROPEUS QUETINHAM INFLUÊNCIAS DA FENOMENOLOGIA: MAX PAGÈS E EUGENE GENDLIN}

Em uma entrevista concedida a Edwin Boring e a Gardner Lindzey, em 1967, Carl Rogers pondera sobre a sua relação tardia e incidental com o pensamento fenomenológico. Em suas palavras:

Fiquei surpreso ao constatar, por volta de 1951 (a data de publicação de Terapia Centrada no Cliente), que a direção do meu pensamento e dos aspectos centrais de meu trabalho terapêutico poderiam ser acertadamente classificados como existenciais e fenomenológicos. Parece estranho que um psicólogo americano possa se encontrar em estranha companhia. Hoje essas influências são significantes para a nossa profissão. (Rogers, como citado em Spiegelberg, 1972, p. 156 , tradução nossa)

Rogers (1961/1997) credita esses apontamentos filosóficos aos seus alunos da Universidade de Chicago. Quem foram, porém, esses discentes? Infere-se que, pela data enunciada, Max Pagès possivelmente foi um deles. Após terminar a graduação em Psicologia no Instituto Nacional de Orientação Profissional, na Universidade de Sorbonne, Pagès migrou para os EUA com o intento de estudar aconselhamento psicológico e psicoterapia com Rogers. Versado em Filosofia e em Sociologia, Pagès (1955/1976) ressalta que durante a sua estada, em 1951, na Universidade de Chicago, percebeu em Rogers uma Fenomenologia prática. Segundo o autor, "Rogers quer fazer, a todo o momento, uma síntese entre o método fenomenológico do clínico e o método científico" (p. 8). Após se doutorar, Pagès retornou para a França, onde se tornou professor de Psicologia Social na Universidade de Paris-Dauphine.
Apesar disso, Pagès (1955/1976) critica o pensamento rogeriano como possuidor de várias lacunas decorrentes do individualismo de sua clínica. Para ele, pensar uma abordagem fenomenológica de Rogers implica apontar um aspecto sociológico que convém à superação desse individualismo. Por isso, o trabalho de Pagès (1975/1976) se direciona para uma proposta de trabalho grupal e Psicologia Social influenciada pela orientação não diretiva elaborada por Rogers. Tal proposta estabelece um diálogo da teoria rogeriana com os aportes das fenomenologias de Martin Heidegger e Maurice Merleau-Ponty. Em especial, Rogers (1959/1977) cita o trabalho de Pagès, Orientação não diretiva em psicoterapia e Psicologia Social (1955), que contém essa discussão e crítica. Ou seja, Rogers contatou o pensamento de Pagès e este, possivelmente, foi um dos alunos que lhe indicaram o direcionamento fenomenológico e existencial de seu pensamento. Curioso é notar que Rogers (1970/2002, 1977/2001), nos anos de 1960-1970, passou a se preocupar com os fenômenos grupais e a repercussão social do seu trabalho.

Outro estudante de Rogers que, com certeza, o influenciou em relação ao pensamento fenomenológico foi Eugene Gendlin, filósofo austríaco que se interessou pela psicoterapia centrada no cliente e migrou para Chicago para iniciar, em 1952, o doutorado. Sob a orientação de Rogers, a tese de Gendlin, The function of experiencing in symbolization, defendida em 1958, consistiu na elaboração de uma escala de processos experienciais na clínica para auxiliar intervenções psicoterapêuticas. Para isso, Gendlin cunhou o conceito de experienciação (um neologismo para experiencing) em substituição ao conceito rogeriano de 
experiência. Posteriormente, em 1962, Gendlin publicou os resultados de sua pesquisa no livro Experiencing and the creation of meaning: a philosophical and psychological approach to the subjective.

Influenciado pelos aportes fenomenológicos de Edmund Husserl, Jean-Paul Sartre e Maurice Merleau-Ponty, Gendlin (1962) entendeu a experienciação como um processo contínuo de conhecimento interno que produz sentidos. Trata-se de enfocar os processos de sentir algo em um presente imediato que é de origem organísmica e pré-conceitual. Ao se voltar para o que sente, a pessoa pode elaborar um sentido que se refere, em termos simbólicos, a sua vivência direta de algo. Toda experiência direta tem um caráter pré-conceitual contendo um significado implícito que pode ser acessado desde que contatado no presente imediato.

No que concerne à fundamentação do conceito de experienciação de Husserl, Gendlin (1962) se inspirou na ideia de que todo conhecimento tem um componente pré-predicativo (intuitivo) de mundo, sem palavras; de Sartre, Gendlin (1962) alude à plenitude de um sentido implícito; e de Merleau-Ponty, Gendlin (1962) se apropria da essência da emoção como fonte constituinte da experiência de significação do mundo - a emoção tem mais primazia de conhecimento direto de mundo do que a imaginação e o pensamento.

Gendlin tinha o projeto de fazer uma ponte entre a Filosofia fenomenológica e a psicoterapia de Rogers. Em uma carta dirigida a Herbert Spiegelberg, em 09 de abril de 1970, Gendlin especifica suas intenções sobre Rogers. Para o filósofo austríaco erradicado nos EUA:

O problema básico de Rogers em Terapia Centrada no Cliente [1951] e depois (...) em Sigmund Koch, ed., Psychology: a study of a Science [1959], foi como pensar e medir a congruência entre o self e o organismo, os conceitos básicos de sua teoria. Se o conceito básico era a congruência ou a divergência entre o organismo e o self, como se poderia falar fenomenologicamente sobre isso? Rogers já tinha o desejo de prosseguir fenomenologicamente, mas lhe parecia impossível falar fenomenologicamente da congruência entre o que estaria consciente e do, que por definição, não se tinha conhecimento. Ele se sentia preso a uma concepção basicamente não fenomenológica. Ele queria ser fenomenológico, mas não foi. Minha contribuição foi formular a sua teoria ao longo de linhas fenomenológicas... Ao invés de ver a congruência como uma comparação entre os conteúdos da consciência e o teor do organismo, eu reformulei isso como uma maneira de experienciar um processo, consciente e observável. (Gendlin como citado em Spiegelberg, 1972, p. 154, itálicos do autor, tradução nossa)

Rogers (1961/1997, 1967/1976, 1967, 1969/1979, 1983/1985) cita e referencia em abundância o trabalho de Gendlin (1962) e o seu conceito de experienciação para acenar uma base experiencial de conhecimento direto e implícito de mundo, de onde emergem o conhecimento e o sentido. Curiosamente, somente foi identificado um texto em que Rogers (1964), ao comentar sobre a Fenomenologia, refere-se à Gendlin, para discutir a existência de uma base pré-conceitual da experiência como fonte de conhecimento subjetivo, indicando-a como um conceito de origem fenomenológica. Nos anos de 1960, Gendlin se tornou professor na Universidade de Chicago desenvolvendo uma nova abordagem humanista experiencial chamada Focalização.

Com efeito, a influência fenomenológica de Gendlin sobre Rogers é mais patente do que a de Pagès. Outros estudantes de influência fenomenológica podem ter contatado Rogers, nos anos de $1950 \mathrm{em}$ diante. Todavia, ao ser procurado aproxima-se das influências que se iniciaram próximas ao ano de 1951, na Universidade de Chicago. Considerou-se que os aportes de Pagès e Gendlin tinham uma base mais filosófica europeia do que as influências de Donald Snygg e Arthur Combs em Rogers, nos anos de 1940.

\section{RELAÇÃO DE CARL ROGERS COM ADRIAN VAN KAAM, NA DÉCADA DE I950}

Existem no Brasil poucas menções sobre a relação de Carl Rogers com Adrian van Kaam (Castelo-Branco, 2014). Este é mais reconhecido por ter iniciado e encabeçado as contribuições da Universidade de Duquesne na composição de uma perspectiva de Fenomenologia empírica, elaborando um método de pesquisa qualitativa compreensiva a diversos tipos de experiências (Gomes et al., 2004; De Castro \& Gomes, 2011). A tradição de pesquisa fenomenológica empírica iniciada por van Kaam, segundo Gomes (1997), foi reconhecida por Rogers como uma inovadora perspectiva de investigação em Psicologia Humanista.

Van Kaam foi um pastor holandês que se interessou pela Filosofia e Teologia cristã. Após alguns acontecimentos na Segunda Guerra Mundial, ele se voltou para a prática de aconselhamento como uma possibilidade de oferecer consolo às vítimas da ocupação alemã na Holanda. Dessa experiência veio o seu interesse pela Psicologia e pela Antropologia Filosófica, de onde se influenciou pelas fenomenologias de Jacques de Maritan, Max Scheler, Gabriel Marcel e Karol Wojtyla (posteriormente nomeado Papa João Paulo II). Em 1952, durante um trabalho em Paris, van Kaam recebeu o convite de Vernon Gallagher, presidente da Universidade de Duquesne, em Pittsburgh, para ingressar na Faculdade de Psicologia (Burston, 2008; Muto \& Martin, 2009). Van Kaam, no entanto, deveria fazer uma transição formativa da Teologia à Psicologia.

Ao se mudar para os EUA, em 1954, van Kaan iniciou um doutorado em Psicologia na Case Western Reserve University sob a orientação de Adrian Leo. Nesse período de qualificação, van Kaam estudou com 
Rogers, na Universidade de Chicago e Abraham Maslow, na Universidade de Brandeis, tornando-se amigo deles. Em 1958, van Kaam concluiu o doutorado com a tese The experience of really felling understood by a person: a phenomenological study of the necessary and sufficient constituents of this subjective experience as described by 365 subjects (Muto \& Martin, 2009). Participaram dessa banca de doutorado Carl Rogers, Abraham Maslow e Kurt Goldstein (Spiegelberg, 1972). Posteriormente, a tese de van Kaam foi publicada como artigo no Journal of Individual Psychology, em 1959, com o título Phenomenal analysis: exemplified by a study of the experience of "really felling understood" (Muto \& Martin, 2009).

Basicamente, o trabalho de van Kaam estabelece uma lógica de coleta de dados, por meio de entrevistas e a análise destes pelo que ele denominou como método fenomenológico empírico, distinto do método fenomenológico filosófico. A questão de van Kaam era como estabelecer um rigor de pesquisa empírica nas Ciências Humanas que valorizem os dados imediatos da experiência consciente nas pessoas pesquisadas (Castelo-Branco, 2014). Ainda em 1958, van Kaam iniciara um pós-doutorado, sob a supervisão de Rogers, com o objetivo de estudar comparativamente as teorias da personalidade desenvolvidas por Maslow e Goldstein. Van Kaam fundou um programa de mestrado e doutorado na Universidade de Duquesne com uma orientação fenomenológica de pesquisa e desenvolvimento da Psicologia como uma ciência humana (Muto \& Martin, 2009). Quem mais popularizou e disseminou essa proposta foi um seguidor de van Kaam, Amedeo Giorgi, nos anos de 1960-1970 (Gomes, 1997).

A despeito da proximidade com van Kaam, há poucas menções e referências de Rogers ao seu trabalho. É possível encontrar somente uma referência a van Kaam no artigo de Rogers, Toward a more human science of the person, publicado em 1985, no Journal of Humanistic Psychology. Rogers (1985) reflete o motivo de a Psicologia Humanista não ter exercido impacto na Ciência, em razão da sua escassez de pesquisas empíricas e sua inadequação ao paradigma positivista. Ao exemplificar algumas possibilidades metodológicas para suprir tal escassez empírica, Rogers refere-se ao artigo de van Kaam (1959) como uma possibilidade. Observou-se que, nessa reflexão, Rogers não acena nada em relação à Fenomenologia filosófica, mas indica o método fenomenológico empírico como fonte para pensar outro paradigma de Ciência. No mesmo artigo, Rogers (1985) referencia também, o livro organizado por Giorgi, Phenomenology and psychological research, publicado em 1984. Deste modo, é possível afirmar que Rogers contatou o movimento de Fenomenologia empírica desenvolvido na Universidade de Duquesne.

\section{RELAÇÕES DE CARL ROGERS COM AS OBRAS EXISTENCE (1958) E EXISTENTIAL PSYCHOLOGY (1960), SOB A ORGANIZAÇÃO DE ROLLO MAY}

Rollo May é considerado um dos pioneiros do movimento fenomenológico nos EUA (Spiegelberg, 1972; Gomes \& Castro, 2010). Seus escritos se preocuparam em apresentar para a Psicologia estadunidense o desenvolvimento da Fenomenologia-Existencial no campo da Psiquiatria. Em 1958, Rollo May, Ernest Angel e Henri Ellenberger organizaram e publicaram o livro Existence: a new dimension in psychiatry and psychology, contendo traduções dos textos de alguns daseinanalistas, como Ludwig Binswanger, Eugene Minkowski, Erwin Straus, Viktor von Gebsattel e Roland Kuhn.

Existence é considerado uma obra pioneira na recepção das bases fenomenológicas existenciais da psicoterapia nos EUA (Spiegelberg, 1972), ao passo que, no primeiro capítulo, intitulado The origins and significance of the existential movement in psychology, May (1958) pondera algumas resistências da Psicologia estadunidense a esse movimento de procedência fenomenológica. A principal delas é o entendimento de que a Psicologia e a Psicoterapia de bases filosóficas são consideradas um retrocesso pelos estudiosos dos EUA. No início do livro, May (1958) agradece a Carl Rogers pela revisão e sugestões feitas ao seu texto, conforme a primeira nota de rodapé do capítulo 1. Ainda no mesmo ano, Rogers publicou uma resenha do livro Existence, na Revista Contemporary Psychology.
Esses dados permitem afirmar que Rogers contatou, desde o início, nos EUA, a recepção do movimento fenomenológico e existencial na psicoterapia. Em um simpósio sobre a solidão contemporânea, em 1958, Rogers utilizou um caso clínico de Binswanger como base para discutir a sua teoria da consideração positiva incondicional pelo cliente. $\mathrm{O}$ caso a que Rogers se referiu foi o de Ellen West, cuja tradução integral está na obra Existence. Posteriormente, a palestra de Rogers foi publicada como artigo em 1961 e foi incluída como um capítulo do livro $A$ way of being, em 1980 (Rogers, 1961, 1980). Antes da publicação em inglês, uma parte desse livro foi lançada em português, sob o título de A pessoa como centro (Rogers, 1977).

Posteriormente a Existence, May organizou outra obra chamada Existential Psychology, em 1960, em parceria com Gordon Allport, Abraham Maslow, Herman Feifel e Carl Rogers. Diferentemente de Existence, em Existential Psychology, é possível encontrar mais ideias de psicólogos estadunidenses sobre o movimento fenomenológico existencial na psicoterapia. Em especial, Rogers (1960/1980) aponta ressalvas a esse movimento na Psicologia dos EUA, reivindicando a necessidade de pesquisas empíricas que comprovem os argumentos existenciais de May. Por exemplo, no capítulo Duas tendências divergentes, Rogers (1960/1980) disserta sobre a tensão entre a tendência 
objetiva científica e a tendência existencial filosófica; exemplifica uma possibilidade de conciliação com base em uma pesquisa empírica, realizada por ele e alguns colaboradores, sobre fatores preditivos de delinquência em 75 adolescentes; e utiliza os resultados para discutir e comprovar a noção de liberdade usada por May. Rogers não faz, entretanto, nenhuma menção à Fenomenologia ou a alguma pesquisa fenomenológica empírica.

Observou-se, finalmente, que Rogers e May trilharam duas abordagens humanísticas em paralelo. As influências da Fenomenologia e do Existencialismo são mais próximas a May do que a Rogers. Destarte, pode-se inferir que Rogers contatou indiretamente, via May, diversos aportes do movimento fenomenológico-existencial na clínica. Rogers se permitiu, ainda, a releitura de um caso clínico da Daseinanálise de Binswanger. É importante notar, no entanto, que Rogers não se filiou a tal movimento clínico, não aprofundou uma Filosofia fenomenológica nem situou uma pesquisa fenomenológica empírica em decorrência dele. Rogers ressaltou que se interessou por essa perspectiva de Psicologia, embora não estudasse a Fenomenologia e o Existencialismo (Rogers \& Russell, 2002).

\section{COLABORAÇÃO DE CARL ROGERS COM DOIS LIVROS PIONEIROS À PSICOLOGIA DE INSPIRAÇÃO FENOMENOLÓGICA, NOS EUA, EM I 959 E 1964}

Em 1959, Alfred Kuenzli, docente da Southern Illinois University, organizou um livro intitulado The phenomenological problem. Conforme Kuenzli (1959), a motivação para organizar tal obra foi o conceito de campo fenomenológico, postulado por Donald Snygg, e sua expansão na Psicologia estadunidense, com suporte em suas influências de estudos sobre a personalidade e o comportamento. Reunindo diversos autores com ideias distintas sobre as implicações da Fenomenologia para a Psicologia, Kuenzli (1959) acredita ter organizado um esclarecimento sobre a ênfase fenomenológica na Psicologia estadunidense. Em suas palavras:

Ao invés de voltar para Husserl, que não parece ser especialmente pertinente às preocupações dos psicólogos contemporâneos, talvez os alunos possam vir a desenvolver cada vez mais para os trabalhos aqui apresentados (...). Um psicólogo fenomenológico moderno utiliza todos e quaisquer métodos - como entrevistas clínicas, técnicas projetivas, observação do comportamento e experimentação em laboratório - que podem ajudá-lo a ganhar a compreensão da visão individual da realidade. (p. 9, tradução nossa)

Essa perspectiva demonstra que o movimento fenomenológico na Psicologia estadunidense entendia a Filosofia como um retrocesso, ao passo que incute na Fenomenologia uma visão de ciência preocupada com suas aplicações clínicas, empíricas e experimentais na compreensão do campo fenomenológico de cada indivíduo. Lembra-se que tal ponto de vista se aproxima das resistências apontadas por May (1958) em Existence.

No livro organizado por Kuenzli (1959), constam textos de Snygg, inclusive o artigo The need for a phenomenological system of psychology, Arthur Combs, Carl Rogers e outros. Sobre a participação de Rogers nesse livro, aponta-se que é uma republicação do artigo Some observations on the organization of personality (1947), analisado anteriormente. Lembra-se que, nesse texto, Rogers (1947/1959) não utiliza a dicção campo fenomenológico, mas campo perceptual. Ao se ler essa versão do artigo, em comparação com a versão publicada (Rogers, 1947/2008) no livro organizado por John Wood no Brasil, Abordagem Centrada na Pessoa (2008), observa-se que ambos os textos são praticamente o mesmo. A única exceção é que, na variante estadunidense, Rogers (1947/1958) refere-se o trabalho de Snygg e Combs, Individual behavior: a new frame of reference for psychology (1948). Na versão brasileira, traduzida diretamente da publicação original, o título dessa referência está como manuscrito não publicado. Não resta dúvida de que o contato de Rogers com Snygg e Combs e a publicação do seu artigo, influenciado por eles, possibilitaram a participação no pioneiro livro de Kuenzli sobre o movimento fenomenológico nos EUA.

Em 1964, Thomas Wann organizou o livro intitulado Behaviorism and Phenomenology: contrasting bases for modern psychology. Este contou com as participações de Carl Rogers, Buhhrus Skinner, entre outros autores. A obra é composta pela transcrição de palestras e debates ocorridos na Rice University, em um simpósio organizado pela Divisão de Psicologia Filosófica da Associação Americana de Psicologia para comemorar os 50 anos daquela universidade.

O capítulo de Rogers (1964), Toward a science of the person, não contém referências a nenhum fenomenólogo, mas possui menções, em especial, aos trabalhos de Gordon Allport, Donald Snygg, Arthur Combs, Eugene Gendlin e Richard Jessor, um dos colaboradores do livro The phenomenological problem. Ressalta-se que os livros desses expoentes referenciados por Rogers, possuem alusões à Fenomenologia como um aporte profícuo à Ciência Psicológica.

Rogers (1964) argumenta que acredita no Behaviorismo e aceita sua perspectiva de ciência, mas prefere tentar ir além dela; todavia, ele mantém esperanças de que algum dia exista algum programa de estudos que concilie as perspectivas comportamentais com as fenomenológicas. Rogers (1964) lança um questionamento sobre as consequências do pensamento fenomenológico-existencial e da teoria do self para a pesquisa e teoria em Psicologia. Referindo-se a Gendlin, Rogers (1964) argumenta que toda base de 
conhecimento emerge de um fluxo contínuo de experiência pré-conceitual, o mesmo se aplica para toda ciência objetiva, como a Psicologia Comportamental, que tem um apoio subjetivo de conhecimento. Eis a base de uma nova perspectiva de fazer Ciência que é fenomenológica.

A consequência da Fenomenologia para a Ciência é a assunção de uma Psicologia mais humana, que suplanta a tendência comportamental, desenvolvendo algo além dela. A Fenomenologia na Ciência Psicológica possibilita, pois, a descoberta de perspectivas da pessoa, teorias e métodos. Essa perspectiva pode oferecer contribuições para o Behaviorismo ao mudar de considerações externas sobre a pessoa, baseada em observações do comportamento, para considerações sobre o universo dos sentidos interiores que emergem da sua experiência (Rogers, 1964).

É curioso notar que, ao postular essas implicações fenomenológicas na Psicologia, Rogers (1964) ressalta a necessidade de uma comprovação empírica em pesquisas que abordem a personalidade e outras questões psicológicas. Para ele, tais pesquisas devem explorar as seguintes classes de variáveis: o sentido, o self, sua mudança, a interação psicoterapêutica e o aprendizado pessoal de se observar internamente. Para exemplificar isso, Rogers (1964) refere-se a diversas pesquisas que ele e os seus colaboradores desenvolveram; nenhuma que aplique o método fenomenológico empírico. São pesquisas que utilizavam inventários de personalidade, Teste de Acepção Temática, Técnica Q, escalas de processo e análise semântica do conteúdo da fala do psicoterapeuta. Esses exemplos, ou modelos de pesquisa que Rogers desenvolveu na clínica, são anteriores a sua discussão da inserção da Fenomenologia na Psicologia e não são definidos em outros momentos como pesquisas fenomenológicas ou de inspiração fenomenológica (Rogers \& Dymond, 1954; Roger, 1961/1997). Rogers
(1964) utiliza suas pesquisas, contudo, como exemplos para indicar outra tendência alternativa à ciência vigente e apontar que elas estão imersas em uma terceira força em Psicologia. Possivelmente o autor quis fortalecer o seu argumento com exemplos derivados de sua experiência de pesquisa, pois, em suas palavras, "Esse é o meu julgamento, como eu tento compreender o vigoroso impulso do movimento fenomenológico-existencial em uma variedade de outros campos" (p. 130)

Rogers (1964) argumenta, pois, a necessidade de a Psicologia reconhecer que:

(...) há outra perspectiva. Do ponto de vista existencial, de dentro da estrutura interna fenomenológica de referência, o homem simplesmente não têm características de uma máquina; ele não é simplesmente um ser engatilhado por motivos inconscientes: ele é uma pessoa em processo de criação de si mesmo, uma pessoa que cria significado de vida, uma pessoa que encarna uma dimensão de liberdade subjetiva. (p. 129, tradução nossa)

Finalmente, pondera-se que a participação de Rogers nos livros organizados por Kuenzli e Wann demonstra uma simpatia com um movimento fenomenológico que se estabelecia nos EUA, nas décadas de 1950-1960, inspirado pelo conceito de campo fenomenológico, de Snygg, e pelo uso de pesquisas empíricas para validar seus argumentos. Em específico, Rogers intencionalmente não quis adentrar questões filosóficas mais profundas, o que é uma característica da Fenomenologia, e entende que o movimento fenomenológico na Psicologia aponta para uma visão compreensiva da experiência interna e da personalidade. Rogers intercede para o reconhecimento de uma nova perspectiva de fazer ciência psicológica que é fenomenológica e não comportamental.

\section{ESTADA DE CARL ROGERS NO INSTITUTO OCIDENTAL DE CIÊNCIAS DO COMPORTAMENTO, NA DÉCADA DE 1960}

Ao se aposentar, em 1963, Rogers se mudou para $L a$ Jolla, Califórnia. Nesse período, ele estava desiludido com a academia e o seu jeito rígido de pensar e pesquisar os fenômenos humanos. Ainda que aposentado da universidade e da clínica, Rogers se dedicou ao estudo e às práticas grupais e educacionais. Perto de sua casa, havia o Instituto Ocidental de Ciências do Comportamento, onde trabalhavam dois de seus ex-doutorandos, Thomas Gordon e Richard Farson. Convidado por eles, Rogers se tornou um colaborador associado e pôde realizar práticas grupais e dialogar com cientistas de diversas áreas (Kirschenbaum, 2007). Entre eles, merecem destaque William Coulson e Michael Polanyi com os quais Rogers realizou estudos sobre perspectivas de ciência alternativas às Ciências Comportamentais e ao paradigma positivista. Esses estudos possibilitaram a organização de um simpósio, em 1967, sobre Ciências do Comportamento, suas filosofias e metodologias.

Em 1968, as palestras e os debates desse simpósio foram transcritos no livro Man and science of man. Na palestra de Rogers (1968/1973), este cita o seu trabalho, Toward a science of person (1964), sobre as possibilidades de fazer pesquisa empírica em Fenomenologia. Rogers (1968/1973), entretanto, vai além de um apontamento metodológico, e arrisca o esboço de uma teoria do conhecimento que parte de uma base subjetiva e uma intuição fenomenológica como fonte de conhecimento válido. Rogers comenta, ainda, a existência de um movimento fenomenológico na Psicologia estadunidense e se aproxima da Filosofia do conhecimento tácito, elaborada por Polanyi. 
Em distinção aos escritos anteriores sobre a Fenomenologia, Rogers (1968/1973) se aproxima de um entendimento mais filosófico sobre a experiência subjetiva como base para toda a Ciência. Nesse texto, ele argumenta a Fenomenologia como um paradigma de conhecimento alternativo ao positivismo e apresenta o esboço de uma teoria do conhecimento tácito. Tal apontamento epistemológico, inovador ao pensamento rogeriano, certamente, foi influenciado pelos intensos contatos que Rogers estabeleceu com diversos filósofos da Ciência no Instituto Ocidental de Ciências do Comportamento. Nesse ponto, a Fenomenologia foi entendida como um paradigma de ciência alternativo ao positivismo hegemônico na Psicologia, sobretudo a Comportamental.

\section{ALUSÃO DE CARL ROGERS A UMA PESQUISA FENOMENOLÓGICA EMPÍRICA EM UM WORKSHOP, EM 1970}

Interessado em desenvolver práticas terapêuticas, nos anos de 1960-1970, Rogers elaborou duas modalidades de intervenções grupais: os grupos de encontro e os workshops. Em suma, o grupo é um encontro intensivo, com a média de uma semana, de alguns facilitadores e dezenas de participantes, que acontece em um ambiente não clínico, geralmente hotéis e universidades, com a finalidade de proporcionar crescimento interpessoal e intrapessoal. O workshop, por sua vez, é um movimento grupal ainda mais intensivo, sem facilitadores e composto por centenas de pessoas, que tem a finalidade de proporcionar uma comunidade centrada na pessoa que forme facilitadores e pondere os rumos da Abordagem Centrada na Pessoa (Rogers, 1970/2002).

Rogers, a despeito de se envolver com outros colaboradores na elaboração e na teorização dessas modalidades grupais, não abandonou sua predileção de justificar os seus argumentos e a eficiência de suas intervenções utilizando pesquisas empíricas. No livro Grupos de Encontro, no capítulo $O$ que sabemos através da investigação, Rogers (1970/2002) menciona que fez um estudo sobre 110 pessoas que haviam participado de um workshop (de 500 pessoas) organizado por ele. O objetivo era pormenorizar os processos de mudança de comportamento decorridos dessa experiência grupal. Rogers aponta que, no seu modo de pensar, a leitura de todas as respostas do questionário é fenomenológica. Nesse texto, Rogers (1970/2002) apresenta o questionário estruturado que foi aplicado de modo a coletar informações sobre o significado do workshop realizado.

Observa-se que, nesse texto, Rogers não menciona nenhum fenomenólogo e não situa sua pesquisa em qualquer modelo de pesquisa fenomenológica empírica, ao passo que os seus procedimentos estão distantes dessa perspectiva de coleta (entrevistas semi ou não estruturadas) e análise dos dados (transcrição, leitura geral, divisão em unidades de sentido, técnica de variação livre e imaginária para obter essências e categorização). Ressalta-se que o simples fato de ler as respostas de um questionário não caracteriza uma empiria fenomenológica no sentido de como esta se desenvolveu na Universidade de Duquesne.

Curiosamente, Amedeo Giorgi, um dos desenvolvedores do método fenomenológico empírico, critica o modo de Rogers pensar pesquisas fenomenológicas. Giorgi (1997/2008) argumenta que Rogers entende como fenomenológico tudo aquilo que é experiencial e que esse emprego não significa uma verdadeira Fenomenologia. Foi considerado, portanto, que, embora Rogers tenha contatado o criador do método fenomenológico empírico e fosse simpático a essa perspectiva de pesquisa, ele não desenvolveu essa tradição.

\section{CONSIDERAÇÕES FINAIS}

Este trabalho revisitou as relações de Carl Rogers com o movimento de recepção da Fenomenologia na Psicologia estadunidense, nas décadas de 1940-1970. A lente compreensiva histórica permitiu considerar que Rogers não estabeleceu uma, mas diversas relações com o movimento fenomenológico na Psicologia estadunidense.

Recapitulando as perguntas lançadas por Spiegelberg (1972), que provocaram este estudo, foi procurado respondêlas de acordo com os momentos analisados e discutidos. $\mathrm{O}$ quão diferente é a Fenomenologia Rogers de suas formas tradicionais? Muito, considerando que a forma tradicional da Fenomenologia parte de uma autorreflexão filosófica dotada de um método próprio. Até que ponto ele é devedor da Fenomenologia filosófica? Diretamente, pouco, todavia, ele é devedor de uma linhagem de movimento fenomenológico que se desenvolveu na Psicologia dos EUA, que tinha como característica uma recusa, ou um receio, da Filosofia na Psicologia. Foram argumentados esses apontamentos de modo a identificar o caráter das relações que Rogers estabeleceu com a Fenomenologia.

Constatou-se que Rogers participou da recepção da Fenomenologia na Psicologia estadunidense e foi simpático a esse movimento fenomenológico, embora não tenha elaborado nenhum método clínico, filosófico ou de pesquisa em decorrência dele - apesar de ter tentando ao seu modo. No âmbito da clínica, Rogers percebia a Fenomenologia como uma perspectiva para entender e pesquisar o self. No âmbito da Filosofia, ele tentou esboçar uma teoria do 
conhecimento, utilizando uma base tácita e pré-conceitual da experiência. No âmbito da pesquisa, ele não desenvolveu ou aplicou nenhum método fenomenológico empírico, mas tentou argumentar algo do tipo com base em suas experiências de investigações.

Considerou-se, finalmente, que a relação simpática de Rogers com a Fenomenologia possibilitou diversos entendimentos e desenvolvimentos de sua Abordagem Centrada na Pessoa (ACP) no Brasil. Curiosamente, a ACP foi recebida e circulou no Brasil conforme uma apropriação crítica ao pensamento rogeriano, desenvolvendo um movimento pós-Rogers com orientação fenomenológica e existencial (Moreira, 2010a, Frota, 2012). Por isso, infere-se que no Brasil estuda-se mais Filosofia fenomenológica e suas implicações para a ACP do que nos EUA, em razão das ressalvas dos psicólogos estadunidenses a essa Filosofia. Aponta-se, contudo, a necessidade de outra pesquisa que analise o status corrente de circulação das ideias rogerianas em veículos de produção acadêmica e comprove empiricamente tal inferência.

\section{REFERÊNCIAS}

Amatuzzi, M., \& Carpes, M. (2010). Aspectos Fenomenológicos do Pensamento de Rogers. Memorandum, 19, 11-25.

Burston, D. (2008). In Memorian: Adrian van Kaam (19202007). The Humanistic Psychology, 36(1), 90-91. https://doi. org/10.1080/08873260701829225

Castelo-Branco, P. (2014). Diálogo entre Análise de Conteúdo e Método Fenomenológico Empírico: Percursos Históricos e Metodológicos. Revista da Abordagem Gestáltica, 20(2), 189-197.

Castelo-Branco, P., \& Cirino, S. (2016a). Funcionalismo e Pragmatismo na Teoria de Carl Rogers: Apontamentos Históricos. Revista da Abordagem Gestáltica, 22(1), 12-20.

Castelo-Branco, P., \& Cirino, S. (2016b). Reflexões sobre a Consciência na Fenomenologia e na Abordagem Centrada na Pessoa. Gerais: Revista Interinstitucional de Psicologia, 9(2), 241-258.

Castelo-Branco, P., Rota, C., Miranda, R., \& Cirino, S. (2016a). Recepção e Circulação de Objetos Psicológicos: Implicações para Pesquisas em História da Psicologia. Em R. Assis \& Peres, S (Orgs.), História da Psicologia: Tendências Contemporâneas, 31-50. Artesã.

Castelo-Branco, P., Vieira, E., Cirino, S., \& Moreira, J (2016b). Influências da Psicanálise Neofreudiana na Psicoterapia de Carl Rogers. Contextos Clínicos, 9(2), 279-289. https://doi. org/10.4013/ctc.2016.92.12

Combs, A. (1948). Phenomenological Concepts in Nondirective Therapy. Journal of Consulting Psychology, XII, 197-267. https://doi.org/10.1037/h0061905

De Castro, T., \& Gomes, W. (2011). Movimento Fenomenológico: Controvérsias e Perspectivas na Pesquisa Psicológica. Psicologia: Teoria e Pesquisa, 27(2), 233-240. https://doi. org/10.1590/S0102-37722011000200014

Frota, A. (2012). Origens e Destinos da Abordagem Centrada na Pessoa no Cenário Brasileiro Contemporâneo: Reflexões Preliminares.Revista daAbordagem Gestáltica, 18(2), 168-178.

Gendlin, E. (1962). Experiencing and the Creation of Meaning: A Philosophical and Psychological Approach to the Subjective. The Free Press of Glencoe.

Giorgi, A. (1997/2008). Sobre o Método Fenomenológico Utilizado como Modo de Pesquisa Qualitativa nas Ciências Humanas: Teoria, Prática e Avaliação. Em J. Poupart, J. Deslauriers, L. Groulx, A. Laperrière, R. Mayer, A. P. Pires, M. Jaccoud, A. Cellard, G. Houle, \& A. Giorgi (Orgs), A Pesquisa Qualitativa: Enfoques Epistemológicos e Metodológicos (A. Cristina, Trad.) (pp. 386-409).Vozes.

Gomes, W. (1997). A Entrevista Fenomenológica e o Estudo da Experiência Consciente. Psicologia USP, 8(2), 305-336. https://doi.org/10.1590/S0103-65641997000200015

Gomes, W. B., \& Castro, T. G. (2010). Clínica Fenomenológica: do Método de Pesquisa para a Prática Psicoterapêutica.
Psicologia: Teoria e Pesquisa, 26(esp), 81-93. https://doi. org/10.1590/S0102-37722010000500007

Gomes, W., Holanda, A., \& Gauer, G. (2004). História das abordagens humanistas em psicologia no Brasil. Em M. Massimi (Org.), História da psicologia no Brasil do Século $X X$ (pp. 105-129). E.P.U.

Kirschenbaum, H. (2007). The Life and Work of Carl Rogers. PCCS Books.

Kuenzli, A. (1959). Preface. Em E. A. Kuenzli (Org.), The Phenomenological Problem, vii-x. Harper \& Brothers Publishers.

May, R. (1958). The Origins and Significance of the Existential Movement in Psychology. Em R. May, E. Angel, \& H. Ellenberger (Orgs.), Existence: A New Dimension in Psychiatry and Psychology (pp. 3-36). Basic Books.

Moreira, V. (2010a). Revisitando as Fases da Abordagem Centrada na Pessoa. Estudos de Psicologia (Campinas), 27(4), 537-544. https://doi.org/10.1590/S0103-166X2010000400011

Moreira, V. (2010b). A Gestalt-Terapia e a Abordagem Centrada na Pessoa São Enfoques fenomenológicos? Revista da Abordagem Gestáltica, 15(1), 3-12. https://doi.org/10.1590/ S0103-166X2010000400011

Muto, S., \& Martin, F. (2009). Portrait of Adrian van Kaam and Humanistic Psychology. Journal of Humanistic Psychology, 49(3), 355-375. https://doi.org/10.1177/0022167809333998

Pagès, M. (1955/1976). Orientação Não Diretiva em Psicoterapia e Psicologia Social (A. Santos, Trad.). EDUSP.

Pagès, M. (1975/1976). A Vida Afetiva dos Grupos: Esboço de uma Teoria da Relação Humana (L. Ribeiro, Trad.). EDUSP.

Rogers, C. (1947/1959). Some Observations on the Organization of Personality. Em A. Kuenzli (Org.), The Phenomenological Problem (pp. 49-75). Harper \& Brothers Publishers.

Rogers, C. (1961). The Loneliness of Contemporary Man as Seen in the Case of Ellen West. Review of Existential Psychology and Psychiatry, 1, 94-101.

Rogers, C. (1964). Toward a Science of the Person. Em T. Wann (Org.), Behaviorism and Phenomenology: Contrasting Bases for Modern Psychology (pp. 109-131). University of Chicago Press.

Rogers, C. (1967). The Therapeutic Relationship and Its Impact: A Study of Psychotherapy with Schizophrenics. University of Wisconsin Press.

Rogers, C. (1968/1973). Algumas Reflexões Referentes aos Pressupostos Atuais das Ciências do Comportamento. Em C. Rogers \& W. Coulson (Orgs.), O Homem e a Ciência do Homem (pp. 55-80). Interlivros.

Rogers, C. (1967/1976). Em Busca de Uma Perspectiva Moderna de Valores: O Processo Valorizador da Pessoa Madura. Em C. Rogers \& B. Stevens (Orgs.), De Pessoa para Pessoa: O Problema de Ser Humanos - Uma Nova Tendência 
na Psicologia (M. Leite \& D. Leite, Trads.) (pp. 13-30). Pioneira.

Rogers, C. (1959/1977). Teoria e Pesquisa. Em C. Rogers, \& M. Kinget, Psicoterapia e Relações Humanas: Teoria e Prática da Terapia Não-Diretiva (M. Bizzotto, Trad.), 143-274. Interlivros.

Rogers, C (1977). Ellen West - e Solidão. Em C. Rogers, \& R. Rosenberg, A Pessoa como Centro (pp. 91-101). EPU.

Rogers, C. (1969/1979). Liberdade para Aprender (E. Machado \& M. Andrade, Trads.). Interlivros.

Rogers, C. (1980). A Way of Being. Mariner Books.

Rogers, C. (1960/1980). Duas tendências divergentes. Em R. May (Org.), Psicologia Existencial (pp. 97-106). Globo.

Rogers, C. (1983/1985). Liberdade de Aprender em Nossa Década (J. Abreu, Trad.). Artes Médicas.

Rogers, C. (1985). Toward a More Human Science of the Person. Journal of Humanistic Psychology, 25(4), 07-24. https://doi. org/10.1177/0022167885254002

Rogers, C. (1951/1992). Terapia Centrada no Cliente (M. J. Ferreira, Trad.).Martins Fontes.

Rogers, C. (1961/1997). Tornar-se Pessoa (M. Ferreira \& A. Lamparelli, Trads.). Martins Fontes.
Rogers, C. (1977/2001). Sobre o Poder Pessoal (W. Penteado, Trad.). Marins Fontes.

Rogers, C. (1970/2002). Grupos de Encontro (J. Proença, Trad.). Martins Fontes.

Rogers, C. (1947/2008). Algumas Observações sobre a Organização da Personalidade. Em J. Wood, Abordagem Centrada na Pessoa, 45-70. EDUFES.

Rogers, C., \& Dymond, R. (1954). Psychotherapy and Personality Change. University of Chicago Press.

Rogers, C., \& Russell, D. (2002) Carl Rogers: The Quiet Revolutionary - An Oral History. Penmarin Books.

Snygg, D. (1959). The Need for a Phenomenological System of Psychology. Em A. Kuenzli (Org.), The Phenomenological Problem (pp. 03-30). Harper \& Brother Publishers.

Spiegelberg, H. (1972). Phenomenology in Psychology and Psychiatry. Northwestern University Press.

Van Kaam, A. (1959). Phenomenal Analysis: Exemplified by a Study of the Experience of "Really Felling Understood". Journal of Individual Psychology, 15, 66-72.

Vieira, E., \& Pinheiro, P. (2011). Convergências entre a Abordagem Centrada na Pessoa e Soren Kierkegaard. Psicologia Argumento, 29(65), 167-177. 